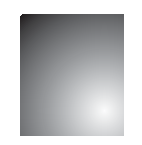

\title{
A Influência da Narrativa Criada por Terceiros na IMAGEM DA MARCA: O CASO DO VÍDEO DO SPOLETO
}

\author{
The Influence of Narrative Created by Third Parties on Brand \\ Image: the case of Spoleto video
}

Fábio Pimenta de Pádua Júnior

Pesquisador de Pós-Doutorado do Programa de Pós-Gradução em Administração da Universidade Federal do Paraná (UFPR).

Curitiba, PR. Brasil. E-mail: pimenta70@gmail.com

Karlan Muller Muniz

Professor Pesquisador na Pontifícia Universidade Católica do Paraná. Curitiba, PR. Brasil. E-mail: karlanmuniz@gmail.com

\section{Resumo}

A narrativa de marca ajuda a formar e a mudar atitudes e crenças, se tornando um importante processo de persuasão. Por ser um tema pouco explorado, o objetivo deste trabalho é analisar a narrativa criada por um terceiro na internet $e$ a sua influência na imagem da marca na qual é feita alusão. São explorados os processos de persuasão narrativa por meio dos mecanismos transportation (imersão dentro de um texto ou estória) e identification (conexão da audiência com o personagem da narrativa). Foram realizadas entrevistas em profundidade, em que os pesquisados assistiram a dois vídeos. A narrativa do primeiro filme é uma paródia e foi criada de modo independente, ao passo que a do segundo é uma resposta da marca. Os resultados encontrados enfatizam a ocorrência do processo de "imersão" na estória e a identificação com os personagens, o que gera um impacto direto na imagem da marca, nem sempre de modo positivo.

Palavras-chave: Persuasão Narrativa. Transportation. Identification. Imagem da Marca.

\section{Abstract}

The brand narrative helps to form and change attitudes and beliefs and is an important persuasion process. Given that this is a relatively unexplored subject, the purpose of this study is to analyze the narrative created by a third party on the Internet, and its influence on the brand image which allusion is made. The narrative persuasion processes using transportation (immersion in a text or story) and identification (audience connection with the character of the narrative) mechanisms are explored. Subjects watched two videos, and after that in-depth interviews were taken. The narrative of the first film is a parody that was created independently, while the second is a response from the brand. The results emphasize the process of "immersion" in the story and identification with the characters, which generates a direct impact on brand image, not always in a positive way.

Keywords: Narrative Persuasion. Transportation. Identification. Brand Image. 


\section{INTRODUÇÃO}

Os investimentos em publicidade no Brasil alcançaram a cifra de $\mathrm{R} \$ 121$ bilhões em 2014, conforme estudo Retrospectiva e Perspectivas do Ibope Media. A TV aberta ainda permanece em primeiro lugar no volume de publicidade (56\%), seguida de jornal (15\%), TV por assinatura (9\%), merchandising em TV (5\%), revista (5\%), Internet $(4 \%)$ e rádio (4\%) (IBOPE MEDIA, 2015). Entretanto, para que todo este investimento seja útil, é necessário que a propaganda seja persuasiva para o consumidor. Neste sentido, a narrativa na publicidade passa a ser um elemento de grande relevância.

A narrativa tem sido descrita como uma abordagem que ainda demanda mais exploração para compreender seu papel na construção de marca e formação do relacionamento consumidor-marca (ALLEN; FOURNIER; MILLER, 2008). É crescente a importância da narrativa no estudo das ações de comunicação da marca (ADAVAL; WYER, 1998; ESCALAS, 2004a; ESCALAS, 2007; PHILLIPS; MCQUARRIE, 2010), que possuem o objetivo de formar e mudar atitudes $e$ crenças do público-alvo.

Investigações contemporâneas confirmam que o processo persuasivo com base em narrativas e seu principal mecanismo subjacente - transportation - têm recebido cada vez mais atenção, o que tem apoiado o avanço em estudos no campo da persuasão (GREEN; BROCK, 2000) e da formação de imagens mentais do consumidor (PETROVA; CIALDINI, 2008).

Muitos estudos que enfocam técnicas de persuasão abordam a narrativa como uma alternativa ao raciocínio argumentativo e a modelos tradicionais de persuasão como o Elaboration Likelihood Model (PETTY; CACIOPPO; SCHUMANN, 1983). Existem trabalhos abordando a diferença entre os dois processos de persuasão na área de teoria da comunicação (FISHER, 2012), na área da psicologia (BRUNER, 1986) e na área de comportamento do consumidor (ESCALAS, 2007), além de referências no estudo da literatura, história, direito e economia (LEONG; ANG; HENG, 1994; ZHENG, 2010). Como resultado de abordagens experimentais, a superioridade da persuasão da narrativa de marca é demonstrada em trabalhos de pesquisa na área de comportamento do consumidor
(DEIGHTON; ROMER; MCQUEEN, 1989; ADAVAL; WYER, 1998; ESCALAS, 2004a; ESCALAS, 2004b; ESCALAS, 2007; LIEN; CHEN, 2011).

No contexto acadêmico brasileiro, foram encontrados poucos estudos envolvendo o foco na narrativa e/ou em aspectos dela que contribuam para a persuasão, o que reforça a necessidade de exploração desse objeto de pesquisa.

Os recursos tecnológicos atuais propiciam o desenvolvimento de narrativas criadas de forma independente. É comum assistir a vídeos na Internet com o depoimento de consumidores insatisfeitos com uma marca, ou então sátiras de propagandas existentes. Outro fenômeno mais recente é a criação de canais no YouTube por grupos humorísticos, com níveis de qualidade profissionais e que são acessados por milhares de pessoas. Os vídeos desses grupos abordam vários temas, sendo comum a criação de esquetes em que são feitas paródias sobre produtos e serviços. Nestas situações, as quais normalmente são constrangedoras, as empresas não têm controle sobre o conteúdo veiculado, podendo ocorrer um desgaste da marca perante seu público-alvo.

Face ao exposto, o objetivo deste trabalho é analisar a narrativa contida em dois vídeos criados por um grupo humorístico veiculados por um canal no YouTube e o seu impacto na imagem da marca na qual é feita alusão.

Pretende-se, por meio deste estudo, destacar a importância do processo de persuasão da narrativa de marca, mostrando que é possível o espectador "entrar" em uma estória e conectar-se com os personagens. Além disso, a aplicação desses mecanismos em um contexto em que uma determinada marca não tem controle sobre a criação da narrativa proporcionará insights importantes para que ela possa entender o impacto de sua imagem perante seu público-alvo.

A próxima seção aborda sobre o impacto da narrativa no comportamento e os processos de persuasão narrativa. Depois são apresentados os aspectos metodológicos desta pesquisa, seguido da análise dos resultados obtidos nas entrevistas. Nas considerações finais são apresentadas as contribuições, aplicações e limitações do estudo, bem como sugestões de pesquisas futuras. 


\section{Referencial Teórico}

A literatura de psicologia defende que as narrativas $^{1}$ servem ao processo de organização cognitiva dos consumidores (POLKINGHORNE, 1991). Muitas das informações e experiências sociais que o consumidor adquire em sua vida são transmitidas na forma de narrativas (ADAVAL; WYER, 1998). Escalas e Bettman (2000) descrevem os consumidores como construtores de estórias, e o maior foco das estórias criadas por eles faz sentido para dizer quem eles são e o que eles consomem.

\subsection{A Comunicação com o Mercado em Formato de Narrativa}

Escalas (1998) conceitua a propaganda de narrativa de forma simples como aquela que conta uma estória, contendo os elementos básicos da narrativa: cronologia e causalidade. Na literatura, a propaganda de narrativa é sempre colocada em oposição à propaganda argumentativa. A propaganda baseada em narrativa conta uma estória, retratando o produto $e$ as consequências ou experiências decorrentes de seu consumo, enquanto a propaganda baseada em argumentos é caracterizada pela demonstração lógica dos atributos do produto (CHANG, 2009), sem um enredo ou personagem definido (DEIGHTON; ROMER; MCQUEEN, 1989). Especificamente, conclui Zheng (2010), a propaganda de narrativa deveria retratar eventos, bem como os personagens que reagem $e$ experienciam tais eventos, e, além disso, o enredo de uma propaganda de narrativa se desenrola ao longo de uma linha de tempo, incluindo as reações dos personagens aos eventos retratados. Em contraste, a propaganda argumentativa não possui enredo e personagem, e convence a audiência de uma afirmação por meio de argumentos lógicos (DEIGHTON; ROMER; MCQUEEN, 1989).

Adaval e Wyer (1998) encontraram evidências de que a comunicação de marketing em formato de narrativa, se comparada com o discurso em forma de descrição das características, leva a melhores avaliações do produto. No caso da pesquisa destes autores, uma

1 É importante esclarecer que os termos "narrativa (narrative) e estória (story)" são usados como sinônimos ao longo deste artigo, tendo em vista o uso alternado de ambos na literatura. viagem de férias descrita em forma de narrativa, em contraste a outra feita por meio de uma lista de características, causou um aumento das reações afetivas do consumidor.

\subsection{Os Processos de Persuasão Narrativa: transportation e identification}

A experiência narrativa é descrita na literatura de psicologia e de comunicação de forma variada, por meio de construtos distintos e que são na maioria das vezes estreitamente relacionados. Sestir e Green (2010) afirmam que identification e transportation são considerados como os maiores moderadores do impacto do consumo de (narrativas de) mídia em seus consumidores.

Elaborado na área de psicologia, primeiramente por Green e Brock (2000), e adotado em trabalhos na área de comportamento do consumidor (WANG; CALDER, 2006; ESCALAS, 2007; PHILLIPS; MCQUARRIE, 2010), o processamento via narrativa afeta a persuasão por meio de um mecanismo chamado transportation, definido por alguns autores como a imersão dentro de um texto/estória (GREEN; BROCK, 2000), ou o processo de informação narrativa no qual uma pessoa não apenas assiste a uma informação, como é absorvida no fluxo da estória, de um modo agradável e ativo (WANG; CALDER, 2006). Green (2004) ainda define transportation como uma mistura integrativa de atenção, imaginário e sentimentos, focados nos eventos de uma estória. Segundo Petrova e Cialdini (2008), nesse processo, quando os indivíduos são transportados para outro mundo, eles não são motivados a corrigir suas crenças e expectativas, porque (a) eles não acreditam que as imagens mentais tenham efeito neles e (b) interromper essas imagens mentais geradas para contra-argumentar a informação pode fazer da experiência algo menos prazeroso.

Ao enfocar o mecanismo transportation como um dos processos centrais envolvidos na persuasão, é relevante relacioná-lo com outra teoria tradicional do mesmo tema, e estabelecer algum contraste. A literatura trata a abordagem de narrativa na comunicação em oposição a modelos de persuasão tradicionais, como o Elaboration Likelihood Model (ELM), (PETTY; CACIOPPO; SCHUMANN, 1983). O ELM apresenta dois possíveis processos de persuasão: a rota central, 
caracterizada pela intensa elaboração cognitiva dos argumentos da mensagem, para altos níveis de envolvimento, e uma rota periférica, quando existe pouca motivação ou habilidade para o processamento de informações, e o receptor usa outras pistas como a atratividade ou atmosfera do anúncio para determinar a adequação $e$ atitude resultantes para com o comercial e com a marca (PETTY; CACIOPPO; SCHUMANN, 1983).

Segundo Green e Brock (2000), no ELM e no HSM (Heuristic-Systematic Model) o elemento crítico é o montante de raciocínio que o indivíduo devota para a mensagem, tornando-o um processo considerado divergente, já que culmina em duas rotas de persuasão. O mecanismo transportation, por sua vez, implica uma imersão no texto/estória, em um processo convergente com um único foco e distante temporariamente de esquemas e reflexões (GREEN; BROCK, 2000). Estes autores argumentam, portanto, que o transportation, resultante da narrativa, não se trata nem advém de um processamento central ou periférico, sistemático ou heurístico, mas de outro processo de persuasão totalmente diferente.

Quando se trata da experiência narrativa, um mecanismo paralelo e com alguma semelhança com o transportation ocorre, segundo as teorias da comunicação: o efeito de identification. A audiência se conecta com o personagem da narrativa. Segundo Cohen (2001), identification é o mecanismo pelo qual membros da audiência experienciam a recepção $e$ interpretação de uma estória "de dentro", como se os eventos estivessem acontecendo com eles. De forma simples, é a imersão de alguém no ponto de vista do personagem (COHEN, 2001; CARPERNTER; GREEN, 2012), processo pelo qual o indivíduo toma indiretamente o lugar do personagem da mídia e reage a suas experiências como se elas estivessem acontecendo com o expectador (SESTIR; GREEN, 2010). Envolve momentaneamente perder a própria identidade, adotando as metas e perspectivas do personagem (OATLEY, 2002).

O relacionamento conceitual entre transportation e identification não é tão nítido (MURPHY et al., 2011). Segundo Busselle e Bilandzic (2008), identification é um processo que acontece em paralelo ao transportation, se for considerado transportation apenas a experiência de construir o modelo mental de uma estó- ria posicionando-se naquele mundo. Carpenter e Green (2012) enumeram três similaridades entre os dois conceitos: primeiro, ambos envolvem um foco profundo na narrativa e um senso subjetivo de "se perder", o que diminui a análise crítica da estória; segundo, ambos são inerentemente afetivos, envolvendo a adoção empática e experiencial da emoção do personagem; terceiro, tanto transportation quanto identification são possíveis em narrativas tanto de ficção quanto de não ficção, em uma variedade de tecnologias e mídias. No entanto, Carpenter e Green (2012) ressaltam que, enquanto o identification é focado na perspectiva de um personagem, o transportation é a absorção do mundo da estória, e que enquanto transportation tende a ser um processo ininterrupto uma vez engajado, o identification é intermitente e facilmente interrompido. Portanto, a narrativa possui potencial para formar ou alterar crenças e atitudes na medida em que um ou dois desses efeitos ocorrem: o consumidor é transportado para dentro da estória retratada e vivencia seu desenrolar; e o consumidor se identifica com o personagem e sua perspectiva. Tais fenômenos, em se tratando de marcas de consumo, podem impactar, além da atitude, a conexão com a marca (ESCALAS, 2004a) e a intenção de compra (ESCALAS, 2007).

Em uma propaganda utilizando a narrativa, a marca assume o papel de personagem, e suas ações e efeitos precisam ser coerentes com a imagem que o consumidor tem a respeito dessa marca. De acordo com Busselle e Bilandzic (2008), os personagens da narrativa são avaliados de acordo com modelos mentais ou estereótipos, e uma inconsistência pode interferir no engajamento com a narrativa, bem como prejudicar seu potencial em entreter, persuadir ou esclarecer. O expectador espera que um policial tenha um comportamento adequado a esta profissão, e um comportamento inesperado, como chorar diante de uma vítima não familiar, pode gerar inconsistência e falta de autenticidade (BUSSELLE; BILANDZIC, 2008). Levando esse raciocínio para o ambiente de marketing, a congruência entre a estória contada na propaganda e a marca que protagoniza tal estória possui implicações no realismo percebido, o que possibilita o efeito de transportation e o impacto nas crenças $e$ atitudes do consumidor. Por outro lado, a falta de congruência pode diminuir o realismo percebido e o nível de transportation, bem como prejudicar o processo de persuasão. 
Em estudos de comunicação e extensão de marcas, fatores como familiaridade e conhecimento da marca têm implicações nos resultados em relação ao comportamento do consumidor (BRONIARCZYK; ALBA, 1994; KENT; ALLEN, 1994). Além disso, a avaliação de uma estória leva em consideração o conhecimento prévio do expectador (GREEN, 2004). Desse modo, é possível inferir que, no ambiente de marketing, a familiaridade do consumidor em relação à marca terá influência na avaliação de uma propaganda cuja narrativa seja incongruente com a imagem e personalidade de marca.

\section{Metodologia}

Quanto à natureza, a pesquisa apresenta caráter qualitativo (BABBIE, 2005), e tem como objetivo a análise do impacto de uma narrativa em relação a uma determinada marca. É um estudo do tipo descritivo, pois possibilita especificar as propriedades relevantes das categorias de análise, e o nível e a unidade de análise são constituídos por indivíduos (MALHOTRA, 2001). O corte da pesquisa foi transversal, tendo em vista que os dados foram coletados em um único ponto no tempo (BARDIN, 2004). A opção por uma abordagem qualitativa foi motivada pelo intuito de compreender em profundidade os elementos que podem influenciar a narrativa de um filme, o que não seria possivel com um levantamento de campo. As categorias de análise e suas extensões são apresentadas a seguir:

a) Familiaridade: nível de extensão das experiências diretas e indiretas que o consumidor tem com a marca avaliada.

b) Imagem: imagem mental e crenças que o consumidor tem sobre a marca avaliada.

c) Transportation: processo de informação narrativa no qual uma pessoa não apenas assiste a uma informação como é absorvida no fluxo da estória, de um modo agradável e ativo.

d) Identification: conexão da audiência com o personagem da narrativa.

e) Realismo percebido: avaliação subjetiva em relação à plausibilidade e realismo dos eventos, ambientes e personagens presentes no vídeo.

f) Atitude em relação à marca: avaliação sobre a marca em termos do quanto ela é atraente, boa, agradável, favorável e simpática. g) Intenção de compra: avaliação do próprio consumidor da probabilidade de que ele irá comprar a marca no futuro.

A coleta de dados foi realizada por meio de entrevistas pessoais em profundidade, com apoio de roteiro semiestruturado e gravação em mídia eletrônica. O roteiro foi elaborado de acordo com as categorias de análise. Segundo Duarte e Barros (2005), a entrevista individual em profundidade é uma técnica qualitativa que explora um assunto, a partir da busca de informações e percepções do entrevistado para análise e apresentação estruturada. A utilização da entrevista semiestruturada permite criar uma estrutura para comparação das respostas e articulação dos resultados, possibilitando descrição e análise em categorias.

Todas as entrevistas gravadas foram transcritas e analisadas por meio de técnica de análise de conteúdo, com o propósito de identificar os elementos definidos neste estudo. Essa técnica foi escolhida tendo em vista que a análise de conteúdo é um conjunto de procedimentos sistemáticos que tem o objetivo de descrição do conteúdo de mensagens codificadas qualitativas ou não (BARDIN, 2004). O recurso da gravação se fez necessário, pois possibilitou o registro literal e integral da entrevista, oferecendo maior segurança à fonte (DUARTE; BARROS, 2005).

Foram realizadas seis entrevistas em profundidade, composta por seis pessoas residentes em uma grande cidade na região Sul do Brasil. A seleção dos entrevistados foi intencional, tomando-se por base a conveniência e a acessibilidade do pesquisador aos dados (FLICK, 2009). Além disso, com o intuito de evitar possíveis vieses, foram selecionadas pessoas que não haviam assistido previamente os vídeos desta pesquisa e que fazem refeições em Shopping Center com pouca frequência. A amostra foi composta por três homens (JC, 43 anos, economista; RP, 49 anos, engenheiro; MG, 60 anos, advogado) e três mulheres (GC, 30 anos, farmacêutica; RG, 55 anos, pedagoga; MR, 69 anos, professora). Seguindo as recomendações metodológicas de Babbie (2005) e Creswell (2003), os entrevistados ficaram à vontade para falar livremente, com o objetivo de favorecer uma atmosfera informal em que as respostas fossem as mais autênticas possíveis.

Para possibilitar a análise da narrativa, foram escolhidos dois vídeos protagonizados por atores do grupo humorístico Porta dos Fundos, veiculados pelo YouTube. Os vídeos escolhidos foram Spoleto e Spoleto 
parte 2. O primeiro faz uma sátira sobre um restaurante do tipo fast-food, onde o cliente escolhe seu prato e os ingredientes no balcão. Neste filme, o atendente é extremamente grosseiro diante da indecisão de um cliente em escolher entre as diversas opções. Interessante observar que em nenhum momento aparece o nome do restaurante, sendo a única indicação direta feita pelo nome do vídeo - Spoleto - que é uma clara alusão ao referido estabelecimento. O segundo vídeo representa uma resposta ${ }^{2}$ da marca, em que mostra a trajetória do mesmo atendente, desde sua demissão após o incidente apresentado anteriormente, até sua readmissão e treinamento. $\mathrm{Na}$ parte final do filme, o atendente agora está sendo diretamente supervisionado, para tentar controlar sua impaciência diante de um cliente extremamente indeciso. Entretanto, ele ainda apresenta uma atitude irônica. Desta vez a marca aparece ao longo do vídeo, e no final há uma mensagem de retratação do Spoleto, indicando que um mau atendimento não deveria ocorrer, mas, às vezes, foge do controle da empresa, a qual agora oferece um canal de atendimento para possíveis reclamações.

O processo de entrevista foi dividido em duas etapas. Na primeira, foi avaliada a familiaridade e a imagem sobre restaurantes do tipo fast-food que servem massas em praças de alimentação de shoppings. Em seguida, o entrevistado assistiu ao vídeo Spoleto, e respondeu perguntas relacionadas sobre o mesmo. $\mathrm{Na}$ etapa seguinte, o entrevistado assistiu ao vídeo Spoleto parte 2 , respondeu a perguntas relacionadas sobre o mesmo, além de avaliar de modo geral o impacto dos vídeos sobre a imagem da marca do restaurante em questão.

\section{Análise e Discussão dos Resultados}

A interpretação e a análise dos dados coletados foram realizadas de acordo com as categorias de análise. As variáveis familiaridade e imagem foram avaliadas antes dos vídeos, e dizem respeito ao tipo de restaurante. Para evitar algum tipo de viés, nesta etapa não foi mencionada a marca Spoleto.

2 O primeiro vídeo foi produzido pelo Kibe Loco e protagonizado pelos atores do grupo humorístico Porta dos Fundos. A marca Spoleto entrou em contato com os produtores e resolveu patrocinar um segundo filme, que representa uma resposta da marca e um pedido de desculpas aos seus clientes (ENDEAVOR, 2014).

\subsection{Familiaridade}

Quando questionados sobre seu conhecimento a respeito de restaurantes do tipo fast-food que servem massas em praças de alimentação de shopping centers, todos os entrevistados afirmaram que conhecem, mas no geral não costumam ir com muita frequência. Uma delas, RG, disse que evita ir "porque engorda". Outro entrevistado, RP, contou que é uma alternativa quando está com pressa ou quando vai ao cinema localizado no shopping center.

Ao final das entrevistas, todos comentaram que já foram ao Spoleto, exceto a entrevistada MR, que afirmou não conhecer a referida marca.

\subsection{Imagem}

A imagem que os entrevistados têm deste tipo de lugar para comer é positiva de um modo geral, destacando a "praticidade, agilidade, grande quantidade de opções de escolha e de cardápio, onde se pode montar o prato" (entrevistada GC). De acordo com a entrevistada RG, "os alimentos servidos neste tipo de restaurantes são gostosos, tem visual atrativo, mas devem ser comidos com moderação, em horários de lanche, e não como refeição principal". Apesar da boa imagem de um modo geral, dois respondentes afirmaram que ainda preferem o restaurante tradicional, por entender que o atendimento e o sabor não são os mesmos. De acordo com o entrevistado JC, por ser uma refeição rápida, apresenta "menos qualidade do que o restaurante tradicional de massa, onde acredita que o molho e outros ingredientes não terão o mesmo sabor e qualidade" (JC). Para a entrevistada MR, que não possui familiaridade com este tipo de restaurante, a imagem que tem é de que, por ser uma refeição rápida, nem sempre será bem servida e, motivado pela pressa, o atendimento tende a não ser adequado.

As variáveis transportation, identification, realismo percebido, atitude em relação à marca $e$ intenção de compra foram medidas em dois momentos, logo após cada um dos vídeos apresentados.

\subsection{Transportation e Identification}

O construto transportation é uma mistura integrativa de atenção, imaginário e sentimentos, focados 
nos eventos de uma estória (GREEN, 2004). Estes elementos foram observados ao longo do processo das entrevistas. A análise de conteúdo revelou que, de um modo geral, a narrativa do primeiro filme prejudicou a imagem da marca. Ficou evidente o efeito de transportation, no qual foi constatada a imersão dentro da estória como um todo (GREEN; BROCK, 2000) por todos os entrevistados, os quais conseguiram se imaginar na cena, no lugar do consumidor, apesar do exagero exibido. Três deles se lembraram de situações similares. A entrevistada GC afirmou já ter se sentido pressionada pelo funcionário, tendo em vista que ela tem tendência a demorar para escolher. O entrevistado $\mathrm{JC}$ disse que geralmente isso acontece com ele quando vai ao Spoleto ou em outros locais onde tem que escolher diferentes ingredientes. A entrevistada RG disse que algo parecido aconteceu com ela quando estava no Subway montando um sanduíche. Não teve tanta pressão quanto no filme, mas acha que "para este tipo de coisa a pessoa teria que escolher antes". Segundo o entrevistado RP,

[...] o vídeo é algo bem exagerado, mas que é natural se uma pessoa ficar dez minutos escolhendo, o negócio se torna impossível. Mas tem uma certa tensão, e por isso o vídeo é engraçado. É uma experiência que você passa. A maioria das pessoas prefere se servir, e ali o atendente vai pegar a quantidade que ele acha que é a certa, e isso já te deixa estressado. Além disso, são muitas opções, e você tem que escolher um determinado número [de opções] e tem gente atrás, você se sente pressionado.

Em relação a aspectos emocionais, todos os entrevistados afirmaram que emergiu algum tipo de sentimento durante a narrativa do primeiro vídeo, principalmente o de se sentir pressionado. Uma das entrevistadas disse que ficou até com dor no peito, que foi ficando tensa com a protagonista e sentiu-se péssima. Além disso, foram reportados sentimentos de revolta e tristeza ao se imaginarem no lugar do consumidor.

Em suma, os respondentes tiveram uma tendência de se colocar no lugar do cliente na narrativa do primeiro vídeo, em que emergiu um sentimento bastante negativo, de raiva, tensão e pressão. Oque, por sua vez, evidencia o surgimento do mecanismo identification, no qual membros da audiência experienciam a recepção e interpretação de uma estória "de dentro", ou seja, a imersão de alguém no ponto de vista do personagem, como se os eventos estivessem acontecendo com eles (CARPERNTER; GREEN, 2012; COHEN, 2001; SESTIR; GREEN, 2010). Tendo em vista o processo de identificação unânime com o cliente, o qual foi muito maltratado, tanto a imagem da marca quanto a intenção de compra foram prejudicadas na primeira narrativa.

O segundo vídeo mostra o esforço da marca em melhorar o atendimento por meio de treinamento e outras ações. Neste filme, o protagonista da estória passa por outros empregos que são piores e acaba voltando ao restaurante, desta vez sob a supervisão de um gerente. Além disto, o cliente mostrado nesta narrativa é mais indeciso do que a da primeira. Depois de assistir ao segundo filme, todos afirmaram que conseguiram se imaginar na cena, ou seja, os elementos contidos nesta segunda narrativa também geraram claramente os efeitos de transportation e identification. Entretanto, alguns entrevistados não conseguiram se imaginar no lugar do consumidor. Nesta segunda narrativa, a identificação mais forte foi com o atendente, pois conseguiram se colocar no lugar dele de modo natural. Assim, o sentimento mais forte reportado foi o de frustração, coerente com a situação do personagem. "Como é difícil a vida dele", afirmou o entrevistado RP. Ainda segundo ele, "você ficou 15 minutos na fila e quer saber se tem uma coisa que está na sua frente?" Para a entrevistada RG, um cliente "tão indeciso como a moça do filme é uma tortura". Para os demais participantes que se identificaram com o consumidor, constatou-se que continuou o sentimento de estar sendo pressionado, mas de modo um pouco mais moderado.

\subsection{Realismo Percebido}

Esta variável foi avaliada em função da plausibilidade e do realismo dos eventos, cenários, narrativa e personagens presentes nos vídeos. No geral, cinco dos respondentes acharam que no primeiro filme o cenário e a narrativa eram realistas e acreditáveis, porém de modo muito exagerado. Em relação ao personagem, o entrevistado JC afirmou que "uma pessoa que não sabe o que quer, e vai lá num horário de pico, fica constrangida e acaba escolhendo o que não quer". De acordo com a entrevistada RG, apesar do exagero do filme, ela acredita que na vida real costuma ocorrer algo parecido, não verbalizado, retratado apenas pelo 
olhar do funcionário. "Um olhar que diz: Vai ou não vai? Desembucha, saia da fila!" Entretanto, para a entrevistada GC, "o cliente não teria um comportamento tão passivo". Outro entrevistado, RP, não imagina alguém atirando o palmito, tão pouco acredita que um cliente começaria a chorar naquela situação. Mas para ele, é justamente isto que deixa o filme engraçado.

As opiniões não mudam muito após terem assistido ao segundo vídeo. Para dois respondentes, o filme foi mais real do que o primeiro, mas ainda assim é exagerado. Para a entrevistada RG, caso não tenha um gerente por perto, é possível que o atendente seja irônico com um cliente indeciso. $\mathrm{O}$ entrevistado RP achou que a mensagem é interessante, pois ela vai para os dois lados. Para o balconista, para que ele atenda bem o cliente, mas também dá uma dica sutil para o cliente, o qual deveria escolher antes de chegar sua vez. Apenas um participante - a entrevistada MR afirmou que nenhum dos eventos retratados em ambas as narrativas poderia ter acontecido na realidade, pois "seria muita falta de respeito ao consumidor".

\subsection{Atitude em Relação à Marca}

Foi realizada uma avaliação sobre a marca em termos do quanto ela é atraente, boa, agradável, favorável e simpática. Tendo em vista que no primeiro vídeo não aparece a marca, os entrevistados avaliaram o restaurante em si. As opiniões foram divididas. Para a entrevistada GC, foi "completamente desagradável, surreal". De acordo com a entrevistada MR, "no início do filme, o restaurante passa a impressão de ser um lugar bom, mas depois ele se torna muito desagradável". Ela afirmou que se estivesse ao lado da pessoa que estava sendo mal atendida, teria ido embora. Para o entrevistado JC, é um "restaurante normal de shopping center, nem bom nem ruim". O entrevistado RP avaliou o restaurante como neutro, pois o filme mostra apenas o espaço em que se faz o pedido, e não aparece o local onde as pessoas sentam para comer. A entrevistada RG achou o ambiente limpo e organizado, e o entrevistado MG deu a melhor avaliação, afirmando que daria nota oito para o local retratado no filme.

Após os participantes assistirem ao segundo vídeo (em que aparece a marca Spoleto), constatou-se que houve uma mudança de atitude em relação ao restaurante retratado no filme. A entrevistada GC, que gosta da marca, acredita que independente do vídeo a marca continua sendo boa. "O primeiro filme denegriu um pouco a imagem do restaurante, mas no segundo vídeo, a atitude do gerente em treinar melhor o funcionário recupera a imagem boa da marca". O entrevistado MG disse que quando foi ao Spoleto foi bem atendido. Ele havia dado nota oito no primeiro vídeo e agora daria nota nove e meio. Para ele, a imagem da marca melhorou. O entrevistado JC vê o restaurante como uma empresa preocupada com o consumidor. Afirmou não ter percebido mudança de atitude, pois a imagem que tinha da marca era positiva e os filmes não alteraram este fato. Outros entrevistados acharam que foi uma boa ideia da marca fazer o segundo vídeo, pois passou a sensação de que a empresa se importa com o cliente e quer que ele tenha um bom atendimento e uma boa experiência. $\mathrm{O}$ entrevistado $\mathrm{RP}$ acredita que houve mudança de atitude, pois se ficasse somente com o primeiro vídeo, teria a impressão de ser um lugar sujo, bagunçado, onde o cliente não é bem recebido. No segundo filme, ele passou a ter a "impressão de que eles vão pegar a pessoa mais sem paciência $e$ transformá-la num bom atendente, e que se isso não acontecer, você pode reclamar para eles, pois será ouvido. Isto é uma preocupação deles".

\subsection{Intenção de Compra}

Quando questionados se fariam uma refeição no restaurante retratado no primeiro vídeo, quatro participantes afirmaram que sim. Para eles, foi um problema específico do atendente, e não do estabelecimento. Entretanto, a entrevistada GC afirmou que talvez fosse para acompanhar alguém, mas não faria uma refeição por vontade própria. Já a entrevistada MR afirmou que não iria mesmo se fosse convidada, por medo de ser mal atendida.

Observou-se que a intenção de compra melhorou depois dos participantes assistirem ao segundo vídeo. Cinco participantes afirmaram que fariam uma refeição de livre e espontânea vontade no local retratado no filme, pois perceberam o esforço da marca em solucionar os problemas destacados no primeiro vídeo. A exceção foi a entrevistada MR, que disse que a imagem passada nos vídeos não foi boa, pelo mau atendimento prestado pelos funcionários. 


\subsection{Discussão Geral dos Resultados}

Este trabalho teve como objetivo analisar o impacto da narrativa criada por um terceiro na Internet, que foi capaz de influenciar a imagem da marca na qual foi feita alusão. Para tanto, foram escolhidos dois vídeos disponíveis no YouTube protagonizados pelo grupo Porta dos Fundos. O primeiro foi criado de forma independente, sem a intervenção da marca.

O primeiro aspecto avaliado foi a familiaridade dos entrevistados a respeito do tipo de restaurante retratado nos filmes, ou seja, fast-food que serve massas em praça de alimentação de shopping center. Apesar de afirmarem que são familiarizados, não costumam ir com muita frequência. Entretanto, possuem boa imagem deste tipo de estabelecimento.

A análise das entrevistas também evidenciou o efeito de transportation e identification. Isto era um resultado esperado, pois a familiaridade e o conhecimento da marca ajudam na avaliação de uma estória (GREEN, 2004). A imersão dentro da estória como um todo (GREEN; BROCK, 2000) ficou aparente quando três participantes citaram situações parecidas nas quais já haviam vivenciados. De um modo geral, ao longo da narrativa do primeiro filme, houve uma forte identificação dos respondentes com o consumidor (CARPERNTER; GREEN, 2012; COHEN, 2001; SESTIR; GREEN, 2010), o qual foi muito maltratado. Esta identificação foi tão forte que alguns participantes afirmaram ter ficado tenso e com dor no peito. Este forte sentimento negativo, por sua vez, fez com que tanto a imagem da marca quanto a intenção de compra ficassem prejudicadas.

Importante destacar que houve uma intervenção da marca, que patrocinou a produção de um segundo vídeo, no qual mostra o esforço em melhorar o atendimento por meio de treinamento e outras ações. Novamente, foram observados os efeitos de transportation e identification. Entretanto, nesta segunda narrativa a identificação mais forte foi com o atendente. Assim, o sentimento mais marcante reportado foi o de frustração, coerente com a situação do personagem. Isso fez com que ocorresse uma melhora sensível na imagem da marca e também um aumento na intenção de compra, destacando o poder de persuasão da narrativa.

\section{Considerações Finais}

A análise das entrevistas indica que a narrativa contida em um filme é capaz de "transportar" o consumidor para dentro da estória, ao mesmo tempo em que ele se "identifica" com o personagem, passando por uma experiência tão intensa que ele sente como se os eventos estivessem acontecendo com ele. Como consequência deste processo, passa a assumir o ponto de vista do personagem com o qual ele se identificou. No caso do primeiro filme, todos os entrevistados afirmaram ter se identificado com o cliente que foi maltratado. Isto, por sua vez, afetou a imagem que tinham da marca, além de diminuir a intenção de compra. Com isto, percebe-se que quando uma marca sofre algum tipo de "ataque", é importante que ela prepare uma boa resposta. No caso da marca Spoleto, a empresa foi muito feliz em aceitar as críticas do primeiro vídeo e encarar o desafio de elaborar outro filme, desta vez sob seu ponto de vista. O resultado foi eficaz, pois os entrevistados se identificaram com o funcionário do Spoleto, que tem uma vida sofrida e tem que encarar clientes indecisos. Este fato fez com que eles mudassem a opinião negativa sobre a imagem da marca deixada no primeiro filme, além de aumentar a intenção de compra.

É importante salientar alguns problemas que podem estar escondidos no processo de transportation e identification das narrativas. As pessoas conseguem se "transportar" para a cena da narrativa e tendem a se "identificar" com um personagem de acordo com o papel que assumem mentalmente, $e$ isto vai culminar em uma atitude em relação à marca. Esse processo de identificação aparentemente ocorre em função do perfil da pessoa, e isto pode ser problemático. É muito provável que pessoas que tenham um perfil indeciso, após verem os vídeos, tendam a evitar a marca para não se sentirem pressionadas. Por outro lado, pessoas que apresentam um perfil mais curioso, e que não conheçam a marca, podem se sentir estimuladas a verificar se a narrativa do filme poderia acontecer de fato, ou seja, acabam experimentando a marca.

Em suma, os resultados encontrados neste estudo exploratório evidenciam a importância da narrativa na persuasão e atitude dos consumidores em relação a uma marca. Mostra, também, que as novas tecnologias de comunicação proporcionam oportunidades e armadilhas para as marcas, que devem estar atentas 
ao conteúdo veiculado por terceiros em mídias como o YouTube.

Entre as possíveis aplicações, fica a sugestão para que marcas que tenham sido, de alguma forma, denegridas por narrativas feitas por terceiros, elaborem uma reposta, com o intuito de levar o consumidor a se identificar com o ponto de vista da empresa.

Este estudo apresenta algumas limitações. Por ser de natureza qualitativa, não é possível generalizar os resultados encontrados. Novas pesquisas quantitativas poderiam ser realizadas para corroborar os achados deste estudo. Poderiam ser usados outros vídeos em que não fosse tão evidente o processo de imersão na estória e identificação com os personagens, para verificar se ainda existiria a forte influência da narrativa na imagem da marca.

\section{REFERÊNCIAS}

ADAVAL, R.; WYER Jr., R. The role of narratives in consumer information processing. Journal of Consumer Psychology, [S.I.], v. 7, n. 3, p. 207-245, 1998.

ALLEN, C. T.; FOURNIER, S.; MILLER, F. Brands and their meaning makers. In: HAUGTVEDT, C. P.; HERR, P. M.; KARDES, F. R. (Org.). Handbook in Consumer Psychology. New York: Taylor \& Francis Group, 2008. p. 781-822.

\section{BABBIE, E. Métodos de Pesquisa Survey. Belo} Horizonte: Editora UFMG, 2005.

BARDIN, L. Análise de conteúdo. 3. ed. Lisboa: Edições 70, 2004.

BRONIARCZYK, S. M.; ALBA, J. W. The importance of the brand in brand extension. Journal of Marketing Research, [S.I.], p. 214-228, 1994.

BRUNER, J. Actual minds, possible worlds. Cambridge, MA: Harvard University Press, 1986.

BUSSELLE, R.; BILANDZIC, H. Fictionality and perceived realism in experiencing stories: a model of narrative comprehension and engagement. Communication Theory, [S.I.], v. 18, n. 2, p. 255-280, 2008.
CARPENTER, J. M.; GREEN, M. C. Flying with Icarus: narrative transportation and the persuasiveness of entertainment. In: SHRUM, L. J. (Org.). The psychology of entertainment media: blurring the lines between entertainment and persuasion. New York: Routledge, 2012. p. 11-35.

CHANG, C. C. Being hooked by editorial content: the implications for processing narrative advertising. Journal of Advertising, [S.I.], v. 38, n. 1, p. 21-33, 2009.

COHEN, J. Defining identification: a theoretical look at the identification of audiences with media characters.

Mass Communications \& Society, [S.1.], v. 4, n. 3, p. 245-264, 2001.

CRESWELL, J. W. Research design: qualitative, quantitative and mixed methods approaches. Thousand Oaks: Sage, 2003.

DEIGHTON, J.; ROMER, D.; MCQUEEN, J. Using drama to persuade. Journal of Consumer Research, [S.l.], v. 16, n. 3, p. 335-343, 1989.

\section{DUARTE, J.; BARROS, A. Métodos e Técnicas de} Pesquisa em Comunicação. São Paulo: Atlas, 2005.

ENDEAVOR. Como o Spoleto respondeu às críticas. [2014]. Disponível em: < http://www.endeavor.org. br/artigos/marketing-vendas/relacionamento-comconsumidor/aprenda-com-o-spoleto-a-responder-ascriticas >. Acesso em: 18 abr. 2014.

ESCALAS, J. E. Advertising narratives: what are they and how do they work? In: STERN, B. (Org.). Representing consumers: voices, views and visions. London:

Routledge, 1998. p. 267-289.

ESCALAS, J. E. Imagine yourself in the product. Journal of Advertising, [S.1.], v. 33, n. 2, p. 37-48, 2004a.

ESCALAS, J. E. Narrative processing: building consumer connections to brands. Journal of Consumer Psychology, [S.I.], v. 14 n. 1, p. 168-179, 2004 b.

ESCALAS, J. E. Narrative versus Analytical SelfReferencing and Persuasion, Journal of Consumer Research, [S.I.], v. 34, n. 4, p. 421-429, 2007. 
ESCALAS, J. E.; BETTMAN, J. R. Using narratives and autobiographical memories to discern motives. In: RATNESHWAR, S.; MICK, D. G.; HUFFMAN, C. (Org.). The why of consumption: perspectives on consumer motives, goals, and desires, New York: Routledge, 2000. p. 237-58.

FISHER, W. Narrative paradigm. In: GRIFFIN, E. (Org.).

A First look at communication theory. New York: McGraw-Hill, 2012.

FLICK, U. Desenho da pesquisa qualitativa. Porto Alegre: Artmed, 2009.

GREEN, M. C. Storytelling in teaching. American Psychology Society Observer, [S.I.], v. 77, n. 4, p. 1-8, 2004.

GREEN, M. C.; BROCK, T. C. The role of transportation in the persuasiveness of public narratives. Journal of

Personality and Social Psychology, [S.l.], v. 79, n. 5, p. 701-721, 2000.

IBOPE MEDIA. Investimentos Publicitários de 2014.

[2015]. Disponível em: <http://www.ibopemedia.com/ investimentos-publicitario-de-2014>. Acesso em: 3 jul. 2015.

KENT, R. J.; ALLEN, C. T. Competitive interference effects in consumer memory for advertising: the role of brand familiarity. Journal of Marketing, [S.1.], v. 58, p. 97-105, 1994.

LEONG, S. M.; ANG, S. H.; HENG, L. Using drama to persuade: the effects of involvement and ad form on persuasion. Asia Pacific Advances in Consumer Research, [S.l.], v. 1, p. 261-264, 1994.

LIEN, N. H.; CHEN, Y. L. Narrative ads: the effect of argument strength and story format. Journal of Business Research, [S.1.], v. 66, n. 4, p. 516-522, 2013.

MALHOTRA, N. K. Pesquisa de Marketing: uma orientação aplicada. 3. ed. Porto Alegre: Bookman, 2001.

MURPHY, S. T. et al. Involved, transported, or emotional? Exploring the determinants of change in knowledge, attitudes, and behavior in entertainment-education.

Journal of Communication, [S.1.], v. 61, p. 407-431, 2011.
OATLEY, K. Emotions and the story worlds of fiction. Narrative Impact: Social and Cognitive Foundations, [S.l.], p. 39-69, 2002.

PETROVA, P. K.; CIALDINI, R. B. Evoking the imagination as strategy of influence. In: HAUGTVEDT, C. P.; HERR, P. M.; KARDES, F. R. (Org.). Handbook in consumer psychology. New York: Taylor \& Francis Group, 2008. p. 505-525.

PETTY, R. E.; CACIOPPO, J. T; SCHUMANN, D. Central and peripheral routes to advertising effectiveness: the moderating role of involvement. Journal of Consumer Research, [S.l.], v. 10, n. 2, p. 135-146, 1983.

PHILLIPS, B. J.; MCQUARRIE, E. F. Narrative and persuasion in fashion advertising. Journal of Consumer Research, [S.l.], v. 37, p. 368-392, 2010.

POLKINGHORNE, D. E. Narrative and self-concept. Journal of Narrative and life history, [S.l.], v. 1, n. 2-3, p. 135-153, 1991.

SESTIR, M.; GREEN, M. C. You are who you watch: Identification and transportation effects on temporary selfconcept. Social Influence, [S.I.], v. 5, n. 4, 2010.

WANG, J.; CALDER, B. J. Media transportation and advertising. Journal of Consumer Research, [S.l.], v. 33, n. 2, p. 151-162, 2006.

ZHENG, L. The impact of narrative focus, vividness of product depiction, mental imagery ability, and need for cognition on transportation in narrative advertising. 2010. 109 p. Tese (Doutorado) - The University of Alabama, Tuscaloosa, 2010. 